frequency that does not improve the temper of the gouty patient, but may raise the hope of his physician as to the probability of cure. Other seats of pain are most frequently the insertion of the deltoid muscle and the inner aspect of the upper arm, the ankles, the heels, and the interscapular region. The lower mammary region on the left side is often the seat of pain, as it, indeed, is in many other maladies.

IV. Modifications of Muscular Action.-I. Cardiac palpitation, intermittence or irregularity of pulse, or painful aortic pulsation at and below the epigastrium, often suggest to the patient the presence of cardiac disease ; and it is worthy of remark that, on the one hand, a very great amount of discomfort may often be felt by the patient when the physician can discover no change in sound of heart or rhythm of pulse ; and that, on the other, disease of aortic valves, and other obvious signs of cardiac change, may often be discovered by the physician in a gouty patient, he having never been conscious of any thoracic trouble.

2. Flickering contractions of muscles in the limbs; tonic spasm, with cramp-like pain; and "startings" on falling asleep have often appeared to me to be of gouty origin, and that for the reasons that I have assigned. Priapism, without erotic feeling, is also very common. It sometimes disturbs the sleep, is felt on awaking, but quickly disappears without emission.

3. Local weakness of muscles, such as ptosis, single or double; want of co-ordination of movement of the limbs, both upper and lower, giving an awkwardness of movement and an ataxic gait-are among the symptoms that may have the course and history that I have suggested. I have recently seen several cases of ataxia, and one with marked double ptosis, which had been treated unsuccessfully upon a syphilitic hypothesis, but which recovered speedily when the treatment was based upon a gouty theory.

v. Lastly, there are symptoms beyond those which I have mentioned, and which do not form part of the matter for my description now, but which I will simply enumerate as being further guides or helps in the diagnosis of gouty cases : I. Dyspepsia, cardialgia, distension of stomach and colon with flatus, pyrosis, and acid eructations ; 2. Varicosity of veins, with tendency, upon slight injuries, to occlusion of veins ; 3. Brittleness and vertical lining of the nails of both fingers and toes ; 4. Slight conjunctivitis with occasional chemosis.

The groups of symptoms that I have enumerated rather than described sometimes coexist, sometimes alternate, and their phases are often very puzzling. They present great difficulties in diagnosis and in treatment until the clue is caught. It is often saddening to look through the carefully cherished prescriptions, and especially when they are one's own, and see the long array of drugs that have done no good -iodine, bromine, strychnine, quinine, zinc, iron, silver, cerium, arsenic, valerian, and hops, to say nothing of mercury, bitter infusions, mineral acids, and the like; but then one's sorrow may often be turned into joy-and a joy in which the patient most heartily participates-when a simple treatment, such as I have suggested, is adopted, and all the troubles disappear with a rapidity that seems quite magical, and reminds one of that beautiful process of clearing a photographic picture by cyanide of potassium.

\section{CHEIRO-POMPHOLYX AND DYSIDROSIS}

\section{By ROBERT LIVEING, M.D., F.R.C.P.,} Lecturer on Dermatology at the Middlesex Hospital.

THERE are probably few dermatologists who have failed to notice, from time to time, a disease which Mr. Hutchinson has described as cheiropompholyx, and to which Dr. Thin has recently called attention. A short time ago, a well-marked instance of this affection came under my care. The subject of it was a lad in good health, the son of a medical man living in the country, who had for a long time noticed the affection in his son as something out of the common, and sent him to me for a second opinion. The eruption corresponded exactly with the very accurate description of it given by Dr. Thin; and its recurrent character was well illustrated, for my patient had suffered from repeated attacks. It was in his case confined to the hands, and consisted of vesicles arranged singly or in small groups along the sides and backs of the fingers. The contents of the vesicles were quite clear, and there was no other sign of inflammation in their immediate neigh. bourhood, or on any other part of the body ; there was, in fact, nothing resembling ordinary eczema. I should probably never have seen this case had it not been for the peculiar condition of the nails, which caused my patient annoyance, and which were, as Dr. Thin describes them, "undermined and broken near the root".

Judging from the few well-marked cases of this affection that $I$ have seen, I should regard the following as its chief distinctive features : $\mathbf{I}$. The symmetry of the parts attacked by the eruption ; 2 . Its occurrence chiefly in the hands and feet; 3 . The absence for the most part of other signs of inflammation beyond the development of vesicles or small blebs ; 4. The peculiar condition of the nails ; 5. Its strikingly recurrent character. These features may not be found in every case, but they are certainly generally present. I have never been able to discover that this affection originated in the sweat-ducts or glands; and I fail to see, on that supposition, why the nails should be so often attacked. Further observation will probably determine to what group of skin-affections cheiro-pompholyx should be assigned.

With regard to dysidrosis, I entirely agree with my friend Dr. Tilbury Fox, that the affection he describes under that name exists, and also that it is an affection of the sweat-glands, associated with more or less inflammation. But it is perfectly distinct from cheiro-pompholyx ; and I fail to see in what respect it differs from a local hyperidrosis, giving rise, as it often does, to secondary eczema. Whoever will refer to vol. i of Hebra's Handbook of Skin-Diseases (Sydenham Society's Translations), will find (at page 83 ) an account of local hyperidrosis, corresponding in every respect with what Dr. Fox describes as dysidrosis. In the case to which Dr. Fox refers in the BRITISH MEdical JourNAL (December 8th), he mentions the "oozing out" of the sweat, and, when that was wiped out, a "fresh supply oozed out". So, in his text-book, he remarks (page 476): "The eruption makes its appearance in those who habitually perspire freely." And in speaking (page 478) of the differential diagnosis, the only distinction he draws between hyperidrosis and dysidrosis is, that : "In hyperidrosis, there is a large amount of sweat poured out upon the surface; it is not retained to distend the sweat-follicles." But surely, when we "wipe off" the sweat and a "fresh supply" oozes out, it is not retained in the follicles, nor is it retained in those who "perspire freely".

Hebra, writing many years ago, remarks on the frequency with which hyperidrosis of the hand causes the epidermis to become "saturated with sweat", and to assume a "white colour" ; and again, that " hyperidrosis localis may give rise to eczema in all its grades". The fact is, that in acute local hyperidrosis, when the parts become swollen, there is always more or less retention of sweat in the glands and other tissues.

On the whole, however, I cannot but think that the distinction between dysidrosis and hyperidrosis localis is too shadowy to justify the introduction of a new name for an old disease.

\section{A CASE OF PARALYSIS OF THE DIAPHRAGM WITH PECULIAR LARYNGEAL SYMPTOMS.*}

\section{BY EDWARD LONG FOX, M.D.,} Physician to the Bristol Royal Infirmary.

IN December I875, a boy came under my observation who had been under the care of Mr. Reid of Tenby and Dr. West of London. Mr. Reid's account dated from a month previously. He had found tenderness and pain in the epigastric region, with great enlargement of the abdomen, dulness on percussion over the epigastric, right hypochondriac, and upper part of the umbilical regions. There was a slight sound on inspiration, somewhat like an eructation, but evidently spasmodic and involuntary. This sound increased in intensity day by day, until it became most distressing, sometimes resembling the clucking of a hen, sometimes the noise made by a turkey, and eventually it became like the scream of a peacock. It ceased during sleep; but sleep was very difficult, and henbane had been found the best hypnotic.

Mr. Reid considered the child was suffering from albuminous liver and kidneys ; the more so that, on one occasion, he had found the urine albuminous. But this latter symptom may have been accidental, as the urine was always healthy during the year of my observation of him.

At the date of my seeing him, he was taking a nightly dose of henbane to the extent of two drachms. He seemed a bright intelligent boy. On stripping him, the upper part of the abdomen was very prominent. The respiration was rather forced and wholly thoracic; the diaphragm seemed to be completely inert; and I considered that the prominence and dulness of the upper part of the abdomen were due to the alteration of the position of the liver and other organs caused by this condition of the diaphragm. The respiration was very noisy both on inspiration and expiration, and simulated a peacock's cry pretty closely; it never ceased for an instant, except during sleep. Swallow-

* Read in the Section of Medicine at the Annual Meeting of the British Medical Association in Manchester, August 1877 . 
ing was rather difficult, especially of solids. The eyesight was not as good as before his illness, but he somewhat exaggerated his weakness in this respect. Ophthalmoscopic examination revealed no lesion in the eyes. His general health was otherwise pretty good; but he was both excitable and depressed, from consciousness of the annoyance caused to other people by his noisy breathing. Sensory and motor powers in the limbs were perfect.

The only previous history that seemed to bear upon the causation of these symptoms was that, nearly a year before his present illness began, he had had a severe blow on the cervical region of the spine from a boy at school. My belief was that the boy was suffering from paresis of the phrenic nerves and irritation of the recurrent laryngeal, the results of an irritative condition of the cervical cord induced by the blow. In the absence of post mortem investigation of the cord, the lesion must remain unknown; but it may be presumed that it was entirely connected with the circulation in the spinal cord.

Under gelseminum, and then strychnia, with faradisation used with one pole over the cervical spine and the other along the upper and most prominent part of the epigastrium, the diaphragm in about two months time began to act slightly, and after three months abdominal respiration was restored. His power of swallowing and his eyesight improved, and the dose of henbane was gradually reduced. His mother and he were turned out of several lodgings in consequence of his noisy respiration; but in six months' time this also improved, mainly under the use of strychnia, with the good air of country lodgings, and with farmhouse occupations and food; and it ceased twelve months ago. Whilst he was getting better in this respect, the peacock's cry could always be induced by any loud sudden noise, or, indeed, by anything that caused a jar. He has now been perfectly well for a year, and is able to resume his education.

\section{SUGGESTIONS ON THE HOSPITAL OUT-PATIENT AND OTHER DIFFICULTIES.}

BY FURNEAUX JORDAN, F.R.C.S.,

Surgeon to the Queen's Hospital, Professor of Surgery at Queen's College, Birmingham; Consulting Surgeon to the Women's and the
West Bromwich Hospitals.

THE great evils which follow the attendance of armies of out-patients at our hospitals are now so widely recognised and earnestly discussed, that something will be done for their relief. I am not about to dwell on those evils or their causes. I cannot but think, however, that there is some exaggeration on a few points connected with the widespread inquiry into hospital affairs. What, for instance, is the amoun of improvidence excused by a certainly too indulgent system of hospital relief, compared with the pauperising tendency of the garish ginpalace, the squalid home, and the long absence of any teaching that it is well to have some thought for to-morrow? Are we not, as a profession, unduly alive to the microscopic pauperisation of hospitals, and unduly indifferent to the alpine pauperisation of "drink"? There prevails also a too rose-coloured view of the general benevolence of the medical profession. We are as good as persons in other callings; we are no better. It is frequently said that no other profession is so generous in the gift of time and effort. Comparison, however, is attempted where no comparison is possible. Let us see. A working man marries; the couple have their accidents and ailments; the wife has half a dozen or a dozen confinements; each child teethes, is vaccinated, has measles, mumps, scarlet fever, whooping-cough, diarrhoa, and so on - a long and weary list. If these fifty events necessitated a legal proceeding, we may be sure that large legal charities would exist, and that lawyers would prove to be as self-sacrificing a class as any other.

But now to the objects which this short paper has in view. The number of out-patients is unmanageable, and leads to many evils. The especially urgent cases are robbed of adequate care by a multitude of trivial cases. How came this? The fault lies mainly with hospital physicians and hospital surgeons. They have encouraged mere numbers : an easy task, seeing that the advice was good, the drugs plentiful, and the cost nothing. They have failed to condemn the growing mischief which they should have been the first to see. Lay hospital authorities could scarcely interfere when physicians and surgeons pointed with pride to rumbers, and said, "See what good we are doing". The apparent good has proved a real evil, and it is not unfair to ask those who helped to do the mischief to help now to undo it. I propose to show how this may be done. The numbers of out-patients can best be reduced by hospital physicians and surgeons. There is a clear principle to guide them in doing this. Hospitals should be simply consulting institutions to the poor; they should supply " second opinions" to those who otherwise must go without them. Cases requiring "consultations" are the proper cases for hospital relief. Consulting or second-opinion cases are exceptional cases-cases of urgency, or obscurity, or obstinacy. Let the hospital medical officer, then, ask this question on every case which comes before him: Is this a case of such urgency, or obscurity, or obstinacy, that, if it were in another social position, a second opinion would be suggested or asked for? Yes; then the case is precisely the one needing hospital assistance. But, if the reply be No, as in nine out of ten cases it will be, then let the case, with a few kind words of direction, be referred to family medical advisers, or general, provident, self-supporting, or friendly, or parochial dispensaries. A certain number might with henefit be told to go nowhither and do nothing. T here will follow but little saving of the time and labour of hospital physicians and surgeons. The urgent, obscure, and obstinate cases reed all the attention now given to cases which are not urgent, are clearly understood, are easily treated, or are obviously incurable.

An eminent authority in hospital administration-Mr. Timothy Holmes-suggests that selected cases should be sent to hospitals by family advisers and dispensaries. This is a suggestion of much value as a collateral and later agency in hospital reform, but it would take a long educational period to bring it into operation. When a family adviser chooses to forward a comparatively poor person for an "opinion", every element of hospital fitress is present ; and much experience enables me to say that such cases are most important and instructive. To make this a rule would be an unjustifiable tax on the practitioner's time. At present, however, and probably for some time longer, crowds will come to the hospital ; and the crowds will not first ask the family or dispensary doctor if they may, or if they are fit. Hospital physicians usually, and hospital surgeons occasionally, are in private practice "consultants" also. Clearly, then, they are best able to say "Come" to the proper cases and "Go" to the improper. They have, or ought to have, the needful knowledge; they are on the spot.

By the method now proposed, any physician or surgeon, may to.day, or to-morrow, or next week, hegin an important and much needed reform $-a$ reform which will also tend to greater knowledge, experience, and judgment in the men who carry it out. I venture, further, to say that the time is quickly coming when any hospital physician or surgeon who has a large number of out-patients will be open to one of two charges : either he is seeking notoriety and private ends by unfair means, or he is incapable of judging of what is urgent, or obscure, or obstinate.

The reduction of numbers by a method at once simple, just, and easily put into practice, brings about indirectly another reform. If the numbers of out-patients are reduced nine-tenths, the financial, social, and provident aspect of the out-patient difficulty is also reduced ninetenths. I shall not dwell on this. It is not the duty of physicians or surgeons to pass the out-patients through a financial sieve. But, however the "financial fitness" inquiry be made, or whoever makes it, the task is greatly simplified by reducing the out-patients to one-tenth of their present number.

Another difficulty would be lessened by the transformation of a crowd of trifles into a group of problems. To put continuous investigation in the place of wearisome routine would bring about the highest educational benefits. The out-patient rooms might thus be made as useful for medical instruction and experience as the hospital wards.

One administrative condition is needed to make the changes which are now suggested. The physicians and surgeons must be entirely free to admit suitable and reject unsuitable cases. Without this freedice privilege or ticket system, the subscribers practically select ; and selection by subscribers involves neglect of the most pressing cases. To modify an expression of $\mathrm{De}$ Maistre's, it may be said that "contempt for tickets is the beginning of hospital wisdom". To me it is a real gain to be connected with a hospital where I am able to do that which I believe I ought to do, and that which I now ask others to do.

The unmanageable numbers of out-patients are mostly on the medical side of the hospital. In other words, the out-patient difficulty is largely a physician's difficulty. Seeing that the medical labour is double or treble the surgical, it is surprising that hospital authorities have not seen the need for more physicians than surgeons. As regards outpatients at least, a hospital having four surgeons should have eight physicians. To this the reply will probably be, that physicians cannot be got. I rejoin, that "pure" physicians are more numerous than "pure" surgeons. If a family mtdical adviser, whose private experience is mostly medical, be converted into a hospital surgeon (as our social exigencies require), why should he not be more frequently con- 